\title{
Epidemiology Characteristic and Co-infection Pattern of Pathogens in Patients With Respiratory Tract Infection in Southern China, 2018-2020.
}

\section{Jingyi Liang}

Guangzhou Institute of Respiratory Disease https://orcid.org/0000-0002-0450-552X

\section{Zhufeng Wang}

Guangzhou Institute of Respiratory Disease

\section{Yong Liu}

Guangzhou Institute of Respiratory Disease

Linxiu Zeng

Kingmed Diagnostics

\section{Zhengtu Li}

Guangzhou Institute of Respiratory Disease

Jiamin Liang

Guangzhou Medical University

Hanwen Liang

Guangzhou Institute of Respiratory Disease

Mei Jiang

Guangzhou Institute of Respiratory Disease

Zifeng Yang ( $\sim$ Jeffyah@163.com )

Guangzhou Institute of Respiratory Disease

\section{Research}

Keywords: Respiratory tract infection, southern china, co-infection

Posted Date: May 5th, 2021

DOI: https://doi.org/10.21203/rs.3.rs-475577/v1

License: (c) (i) This work is licensed under a Creative Commons Attribution 4.0 International License. Read Full License 
1 Title page

2 Epidemiology characteristic and co-infection pattern of

3 pathogens in patients with respiratory tract infection in

4 southern China, 2018-2020.

5 Jingyi Liang ${ }^{1 \#}$, Zhufeng Wang ${ }^{1 \#}$, Yong Liu ${ }^{1 \#}$, Linxiu Zeng ${ }^{2}$, Zhengtu $\mathrm{Li}^{1}$, Jiamin

$6 \quad$ Liang $^{3}$, Hanwen Liang ${ }^{1}$, Mei Jiang ${ }^{1}$, Zifeng Yang ${ }^{1}$

7 \# Jingyi Liang, Zhufeng Wang and Yong Liu contributed equally as co-first

8 authors.

9 Authors' Affiliations:

1. National Clinical Research Center for Respiratory Disease, State Key Laboratory of Respiratory Disease, Guangzhou Institute of Respiratory Health, the First affiliated Hospital of Guangzhou Medical University, Guangzhou, Guangdong, China

2. Guangzhou Kingmed Diagnostics Group Co., Ltd., Guangzhou 510120, China.

3. Guangzhou Medical University, Guangzhou, Guangdong, China

${ }^{*}$ Corresponding Authors:

Dr. Mei Jiang, National Clinical Research Center for Respiratory Disease, State Key Laboratory of Respiratory Disease, Guangzhou Institute of Respiratory Health, the First affiliated Hospital of Guangzhou Medical University, 151 Yanjiang Road, Guangzhou, Guangdong, 510120, China. Email: jiangmei927@163.com;

or Dr. Zifeng Yang, National Clinical Research Center for Respiratory Disease, State Key Laboratory of Respiratory Disease, Guangzhou Institute of Respiratory Health, the First affiliated Hospital of Guangzhou Medical 
26 University, 151 Yanjiang Road, Guangzhou, Guangdong, 510120, China.

27 Email: Jeffyah@163.com

28 Key words: Respiratory tract infection; southern china; co-infection

29 Short title: A epidemiology study on respiratory pathogens in southern China

30 Abstract: 347 words; Manuscript: 2298 words; Figures: 5

31

32

33

34

35

36

37

38

39

40

41

42

43

44

45

46

47

48

49

50 


\section{Abstract}

Background: Respiratory tract infections (RTIs) is the highest prevalent disease and southern china has a wide spectrum of respiratory pathogen. The aim of this work was to renew the epidemiology characteristics of respiratory pathogens found in children and adults with RTls from 2018 to 2020 in southern China.

Methods: In this work, a total of 134,552 nasopharyngeal or throat swabs (patients from 407 hospitals) were analyzed, and fourteen respiratory viruses (Influenza A virus, influenza B virus, parainfluenza viruses, respiratory syncytial virus, adenovirus, human rhinovirus, human metapneumovirus, human Coronavirus, human bocavirus, enterovirus, cytomegalovirus, herpes simplex virus, mycoplasma pneumoniae and chlamydia pneumoniae) were detected using PCR/RT-PCR.

Result: The most common respiratory pathogens in southern china were ADV (16.19\%), RSV (15.48\%), RHV (11.51\%), IAV (10.93\%), MP (8.95\%), EBV (8.70\%), PIV (7.67\%), IBV (5.44\%), with IAV and ADV as the most prevalent pathogens in adults $(11.68 \%)$ and children $(17.10 \%)$ respectively. In detail, ADV (16.30\%) and RSV (18.93\%) are most common in 0-4 years old, with IAV (16.68\%), ADV (20.36\%) in 5-14 years old, with EBV $(7.48 \%, 8.74 \%)$, IAV $(15.43,9.76 \%)$ in $15-49 y, 50-64 y$ and IAV $(7.37 \%)$, IBV (2.43\%) in 65-105y. Over three years witnessed an increase in PDR of PIV in 0-4y, 5-14y and 65-105y, and RHV in 5-14y and 15-49y. In month distribution, the positive detection rate of pathogens in adults were generally lower than that in children except for EBV and majority of pathogens has shown a sharp decline in 2020. In Upper RTIs, $77.27 \%$ (17/ 22) of co-infected patients had infection to ADV, 

, 100

with poly-infection to ADV and RHV the highest (8/22). In Lower RTIs, the ADV infected patients showed that its co-infection rate to MP, PIV, RHV or RSV were $19.51 \%(48 / 246), \quad 15.45 \%(38 / 246), \quad 14.63 \%(36 / 246)$ and $14.63 \%$ (36/246) respectively. Only IAV, IBV and EBV were detected in co-infection patients with lower RTIs.

Conclusion: IAV and ADV were the most important respiratory pathogen in adults and children respectively in southern China and cross-reactivity might exist between ADV, RHV, PIV and MP. These should be taken into consideration when they formulate the strategies for co-infection avoidance in patients. (1)

8

2

3

4
95 ${ }^{\circ}$ " s. 


\section{Introduction}

Respiratory tract infections(RTIs) is one of the highest prevalence diseases globally, especially lower respiratory tract infections(LRTIs), which ranks fourth in risk factor resulting the global disease burden reported in 2019[1]. Because of the difficulty of making a rapid diagnosis of the etiologic agent and considerable clinical syndromes overlap, patients with RTIs are often treated with antibiotics, being responsible for a large part of inappropriate antibiotics in humans[2].

Southern China refers mainly to the area to the south of Qinling and Huaihe $\left(103^{\circ} \mathrm{E}-123^{\circ} \mathrm{E}, 22^{\circ} \mathrm{N}-34^{\circ} \mathrm{N}\right)$, accounting for $55 \%$ of residents in China[3] . Southern China was the first place to report some importance respiratory pathogens, such as SARS-CoV[4], H1N1pdm09[5] and lastest SARS-CoV-2[6], with a large number of domestic and wild animals, as well as transient population that includes laborers and business people from home and abroad. The mixing of a diversity of regional populations may trigger the change on the transmission of respiratory viruses. It's imperative to continuously renew the understanding on the pathogens in patients with RTIs.

With a deepening understanding on RTIs, it's well known that the etiology of pathogens differs between children and adult[infectious and journal].Up to now, only two studies[7, 8] on RTIs in southern China have been published . However, those study were conducted based a small sample size $(<20,000)$, and none of them distinguished the epidemiology characteristic between children and adult in detail. Our study thus analyzed the incidences of 14 pathogens grouped by age during the three-year period from January 2018 to 
December 2020, on the meanwhile, we also sought to identify the coinfection pattern on RTIs cases to better guide treatment and prevention strategies.

\section{Method}

This study was approved by the ethics committee of KingMed Diagnostics (reference number: GZKM-2019-24).

\section{Patients and sample collection}

Study participants had all been admitted to one of the 407 hospitals covering southern China from January 2018 to December 2020. A total of 134, 552 nasopharyngeal or throat swabs were collected from patients with RTls from multiple provinces all over the Southern China. Patients with RTls were defined as follows: had a fever $\left(\geq 37.3^{\circ} \mathrm{C}\right)$, accompanied by at least one of these respiratory symptoms, such as cough; uncomfortable pharynx; stuffy nose; runny nose; sneezing; difficulty breathing; breathing distress; chest pain; asthma; and/or pneumonia or tracheitis, as indicated by X-ray, CT, or MRI. Samples were refrigerated at $2-8^{\circ} \mathrm{C}$ in viral transport medium and transported to the laboratory Kingmed Diagnostics (KMD); samples were either immediately tested or stored at $-80^{\circ} \mathrm{C}$ until use. KMD (http://en.kingmed.com.cn) is a commercial independent medical laboratory in China, has obtained ISO/IEC17025, ISO9001, and ISO15189 accreditation[9].

\section{Definition of groups by clinical diagnosis}

The Upper RTIs group consisted of patients with the following symptoms or signs: rhinitis, stuffy nose, runny nose, pharynx congestion, sore throat, tonsil inflammation, and/or cough. 
149 The Lower RTI group consisted of patients with pulmonary symptoms. These

150 symptoms were determined by an X-ray, CT scan, or MRI revealing bronchitis,

151 orterminal bronchitis, tracheitis, or pneumonia, without evidence of other

152 systemic diseases.

\section{Quantitative Real-time PCR for 14 common respiratory viruses}

154 The viral RNA/DNA was extracted from the swabs using the QIAamp Viral 155 RNA Mini Kit (Qiagen, Germany). Influenza A virus (IAV), influenza B virus 156 (IBV), parainfluenza viruses (PIV), respiratory syncytial virus (RSV), 157 adenovirus (ADV), human rhinovirus (RHV), Human Metapneumovirus(HMPV), 158 huamn Coronavirus(HCoV), human bocavirus (HBoV), enterovirus(EV),

\section{Results}

\section{Demographic characteristics}


In this study, a total of 134,552 RTIs cases from 2018 to 2020 covering 15

southern provinces or municipalities in China were analyzed. In all, 26,872 cases were adults and 107,680 were children, and most of them are male with $14,094(52 \%)$ and $63,616(59 \%)$ respectively. The mean age of adults was $50.47 \pm 19.80$ and $3.32 \pm 3.18$ for children. The seasonal distribution of RTIs patients sampled was $23,613(17.55 \%)$ in spring, 32,245(23.96\%) in summer, $44,496(33.07 \%)$ in autumn, and $34,198(25.42 \%)$ in winter. Majority $(83.81 \%)$ of the RTIs came from coastal areas.

As to the clinical diagnosis, $10571(7.86 \%)$ are confirmed as upper respiratory tract infection, $11842(8.80 \%)$ as bronchitis and $34658(25.76 \%)$ as pneumonia, and all of them differs significantly in the distribution between children and adult $(\mathrm{P}<0.05)$. (Table 1)

\section{Viral prevalence}

Among 134,522 cases, the most common respiratory pathogen was $\operatorname{ADV}(16.19 \%), \quad \operatorname{RSV}(15.48 \%), \quad \operatorname{RHV}(11.51 \%), \quad \operatorname{IAV}(10.93 \%), \quad \operatorname{MP}(8.95 \%)$ $\operatorname{EBV}(8.70 \%), \operatorname{PIV}(7.67 \%), \operatorname{IBV}(5.44 \%)$, with $\mathrm{IAV}$ and $\mathrm{ADV}$ as the most prevalent pathogen in adults(11.68\%) and children(17.10\%) (Fig. 1). The infection to ADV, RSV, RHV, MP and PIV were higher in children than in adults, while it's opposite to IAV $(11.68 \%$ vs. $9.63 \%, P<0.05)$. There is no significant difference in positive detection rate between two targeted population in EBV, IBV, CMV, HSV, HCoV and CP(P>0.05) (Table 1).

\section{Age distribution of common respiratory pathogen in three years}


In general, the top two prevalent pathogen are ADV(16.30\%) and RSV(18.93\%) in 0-4 years old, with $\operatorname{IAV}(16.68 \%), \operatorname{ADV}(20.36 \%)$ in 5-14 years old, with $\operatorname{EBV}(7.48 \%, 8.74 \%), \operatorname{IAV}(15.43,9.76 \%)$ in $15-49 y, 50-64 y$ and $\operatorname{IAV}(7.37 \%)$, IBV(2.43\%) in 65-105y (Fig. 2). Moreover, it's observed that over three years witnessed an increase in PDR of PIV in 0-4y, 5-14y and 65-105y, and RHV in 5-14y and 15-49y (Table 2).

\section{Geographical distribution of pathogen infection in adults and children}

In adults, the positive detection rate to EBV was the highest in coastal cities (14.86\%) and that to RHV was the highest in inland cities (26.74\%). The positive rate of EBV, ADV and IBV in coastal cities were higher than that in inland cities ( EBV: $14.85 \%$ vs. $3.95 \%, p<0.01$; ADV: $5.12 \%$ vs. $1.60 \%, p<0.01$; IBV: $5.68 \%$ vs. $2.86 \%, p=0.034)$, while this trend is opposite in $\mathrm{RHV}(2.63 \%$ vs. $26.74 \%, p<0.01)($ Fig. 3A).

In children, the positive rate to MP was the highest in coastal cities (4.05\%) and that to RHV was the highest in inland cities (22.49\%). The positive rate to RSV $(17.47 \%$ vs. $14.82 \%)$ and MP (19.61\% vs. $4.09 \%)$ in coastal cities were higher than in inland cities $(p<0.001)$, but that to ADV $(21.6 \%$ vs. $12.3 \%)$, $\mathrm{RHV}(10.36 \%$ vs. $22.94 \%)$ and $\operatorname{IAV}(9.06 \%$ vs. $14.77 \%)$ were higher in inland cities than in coastal cities $(p<0.001)$ (Fig. 3B).

\section{Monthly distribution of pathogen infection in adults and children}

In general, the positive detection rate of pathogens in adults was generally lower than that in children especially in ADV, RSV and MP. Only the positive detection rate of EBV in adults was generally higher than that in children, and 
detected sporadically throughout the year without obvious seasonal characteristics. Except for RHV and RSV, according to the epidemic curve, majority of pathogens have been suppressed in 2020 .

As to the epidemic peak, it's obvious that ADV peaks in summer (6-8) and winter (12-2), and RHV peaks in summer (6-8) and autumn (9-11), which is basically as the same pattern in all three years. Since June in 2018, the positive rate of RSV reaches a relative higher value periodically in every four months. In 2018 , the positive rate of IAV exceeded $40 \%$ both in June and December, and followed by a IBV peak from March to September in the next year. Interestingly, both two sub-type of influenza virus ran higher at the beginning of 2020.(Fig 4.)

\section{Co-infection pattern in patients with Upper RTls and Lower RTIs}

We analyzed the situation of co-infection of respiratory viruses and 268 cases were infected with at least two virus reported. A total of $22(8.21 \%)$ cases were diagnosed as upper RTIS and 79 (91.79\%) cases were diagnosed as lower RTIs. In Upper RTIs, $77.27 \%$ (17/ 22) of co-infected patients had infection to ADV, with poly-infection to ADV and RHV the highest (8/22). In Lower RTIs, the co-infection of pathogens is in diversity as many as 18 patterns. Further analysis on the ADV infected patients showed that its co-infection rate to MP, PIV, RHV or RSV were $19.51 \%$ (48/246), $15.45 \%$ (38/246), $14.63 \%$ (36/246) and $14.63 \%$ (36/246) respectively. Only IAV, IBV and EBV were detected in co-infection patients with lower RTIs (Fig 5.).

\section{Discussions}


Respiratory tract infections cause a huge burden on society[1]. Research

on this topic at home or abroad is still limited, which is generally based on a single center or a common respiratory virus, such as RSV. Different from previous studies, this study adopted the largest sample size of respiratory pathogens detection data which was collected from various levels of hospitals, disease control centers, health care hospitals or companies from15 provinces in recent 3 years. Covering urban and rural populations of all ages, the study participants are widely distributed and representative. With these advantages, this study focused on the epidemiological characteristics of several common respiratory virus pathogens and explored the co-infection of viruses, which could provide a basis for further epidemiological studies in China, and provide a direction for the study of the mechanism of co-infection.

Based on the epidemiological and exploratory analysis of 134,552 test results, the study mainly revealed the following interesting phenomena. Firstly, we found that the positive rate of RSV, ADV, MP, RHV, IAV and PIV is higher in children, and the positive rate of IBV and EBV is higher in adults, which are basically consistent with the previous results[10]. Besides, based on 206 adult samples, Macfarlane JT et al. considered IBV, IAV, RSV, ADV, and RHV to be highly prevalent respiratory virus[11], Clearly, the results of our study showed that there were fewer types of respiratory viruses at high prevalence in adults. So, we hypothesized that it may explained by our study participants covered a wide range of areas and period, and people have paid attention to personal hygiene and taken good personal protective equipment with the COVID-19 epidemic. 
In terms of geographic distribution, it was found that the positive rate of

most respiratory viruses in coastal areas was higher than that in inland areas, and this phenomenon was greatly related to the suitable temperature and humidity for pathogen transmission. Our results are similar to that of previous study, for example, Wang Wei [12] found that the overall trend of influenza-like cases in Shandong Province was higher in the northeast coastal areas than in the southwest inland areas. Baker RE et al.[13] also found that the influenza peaks increased during the rainy season in the tropics. However, our study also found that the positive rate of RHV was higher in inland areas. We hypothesized that RHV circulating in inland areas are not the same serotype and more virulent as those in coastal areas, which echoes with previous studies[14] that people infected with RHV were more likely to develop asthma in inland areas compared with those in temperate areas .

Regard to the month distribution of pathogens, our results were basically consistent with that of Bing Xu et al.[15], which studied 28,369 hospitalized cases in all age groups from January 2009 to September 2013 in northern and southern China. However, as their study mentioned, ADV exhibited no clear annual seasonality, while we found that ADV peaks in summer and winter. And we speculate it's the difference in period of time, temperature, vapor pressure, air pressure, rainfall and the length of sunlight that led to the incomplete consistence. When compared with one foreign study[16], we found that there was not much comparability due to the different seasonal months and length of time in different countries or regions.

Moreover, we analyzed the situation of co-infection of respiratory viruses. ADV was most commonly co-infected with other respiratory viruses, while IAV and 
IBV were the least, which were in line with the conclusions of other studies[17, 18]. However, Price $\mathrm{OH}$ et al.[18] and Haller $\mathrm{O}$ et al.[19] considered PIV 、 RSV and RHV were not commonly co-infected with other respiratory viruses because of temporary immunity after infection, and our study have shown the possibility. Specially, Our results also showed that RSV did not co-infect with $I A V$. Although the host immune response induce by two virus is different [20-22], we believe that the production of cytokines causes the host to produce cross-antibodies to provide temporary immunity avoiding other respiratory virus infections. Finally, we found that $92 \%$ of co-infections were indicative of lower respiratory viral infection. But due to the lack of clinical data, it was impossible to tell which pattern of co-infection led to more severe clinical outcome.

There were some limitations in our study, which could be summarized as follows. Firstly, the number of samples delivered by each province is not proportional to the population size. In addition, the calculation of positive rates for respiratory viruses in the study might be overestimated due to bias, but the results were still valuable based on a sample size. Finally, the situation of respiratory virus co-infection in China still needed a standardized surveillance networks to assess virus prevalence patterns.

\section{Conclusion}

IAV and ADV were the most important respiratory pathogen in adults and children respectively in southern China. This was the first study to report the the epidemiology characteristic of respiratory pathogens between children and adult in detail. As the prevalence of infection to ADV, RHV, PIV and MP were 
321 high and cross-reactivity might exist between these pathogens, clinicians

322 should take these into consideration when they formulate the strategies for

323 co-infection avoidance in patients.

324

325

326

327

328

329

330

331

332

333

334

335

336

337

338

339

340

341

342

343

344

345 
Ethic approval and consent to particpate

347 This study was approved by the ethics committee of KingMed Diagnostics 348 (reference number: GZKM-2019-24).

349 Consent for publication

$350 \quad$ Not appilcable

351 Availability of data and materials

352 The data that support these findings are available on reasonable request from

353 the corresponding author. Data are not publicly available due to concerns

354 regarding research participant privacy.

355 Competing interests: None reported.

356 Funding/Support: This work was supported by the Youth Foundation Project

357 of Guangzhou Institute of Respiratory Health and National Clinical Research

358 Center of Guangzhou First Medical College (Grant No.2019GIRHQ02)

359 Author's contribution: M.J and Z.F.Y had full access to all of the data in the

360 study and take responsibility for the integrity of the data and the accuracy of 361 the data analysis. All authors approved the final draft of the manuscript for 362 publication.

363 Concept and design: J.Y.L, Z.F.W and Y.L

364 Acquisition, analysis, or interpretation of data: J.Y.L, Z.F.W, L.X.Z, H.W.L, 365 J.M.L

366 Drafting of the manuscript: J.Y.L and Z.F.W

367 Critical revision of the manuscript for important intellectual content: All authors.

368 Statistical analysis: J.Y.L, Z.F.W and Z.T.L

369 Administrative, technical, or material support: H.W.L, J.M.L,

370 Supervision: M.J and Z.F.Y 
376

377

378

379

380

381

382

383

384

385

386

387

388

389

390

391

392

393

394

395

\section{Acknowledgements}

We thank everyone involved in the collection, detection, and date management of the nasopharyngeal or throat swabs.

(1)

(1)

(1)

8

\section{9}

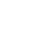




\section{Reference}

1. Berman, A.E., et al., Global burden of 369 diseases and injuries in 204 countries and territories, 1990-2019: a systematic analysis for the. 2020.

2. Doorn, H. and H. Yu, Viral Respiratory Infections. 2020: Hunter's Tropical Medicine and Emerging Infectious Diseases.

3. Luo, W., et al., Allergen sensitization pattern of allergic adults and children in southern China: a survey based on real life data. Allergy Asthma and Clinical Immunology, 2019. 15(1).

4. Rota, P.A., et al., Characterization of a novel coronavirus associated with severe acute respiratory syndrome. Science (New York, N.Y.), 2020(5624): p. 1394-9 页.

5. Kennedy, F., and Shortridge, The 1918 'Spanish' flu: pearls from swine? Nature Medicine, 1999. 5(4): p. 384-384.

6. Wu, J.T., L. Kathy, and G.M. Leung, Nowcasting and forecasting the potential domestic and international spread of the 2019-nCoV outbreak originating in Wuhan, China: a modelling study. Lancet (London, England), 2020. 2020 年 395 卷 10225 期: p. 689-697 页.

7. Liao, X., et al., New Epidemiological and Clinical Signatures of 18 Pathogens from Respiratory Tract Infections Based on a 5-Year Study. Plos One, 2015. 10(9): p. e0138684.

8. Zhang, D., et al., Epidemiology characteristics of respiratory viruses found in children and adults with respiratory tract infections in southern China. Jiangsu Medical Journal, 2014. 25: p. 159-164. 
9. Luo, W., et al., Allergen sensitization pattern of allergic adults and children in southern China: a survey based on real life data. Allergy Asthma Clin Immunol, 2019. 15: p. 42.

10. Ruuskanen, O., et al., Viral pneumonia. Lancet, 2011. 377(9773): p. $1264-1275$.

11. Macfarlane, J.T., et al., Prospective study of aetiology and outcome of adult lower-respiratory-tract infections in the community. Lancet, 1993. 341(8844): p. 511.

12. 王伟, 2009-2014 年山东省流感样病例流行特征及其与气象因素关系研究. 2016, 山东大学.

13. Baker, R.E., et al., Epidemic dynamics of respiratory syncytial virus in current and future climates. Nature Communications, 2019. 10(1): p. 5512.

14. Feddema, J.J. and E. Claassen, Prevalence of viral respiratory infections amongst asthmatics: Results of a meta-regression analysis. Respiratory Medicine, 2020.

15. Xu, B., et al., Seasonal association between viral causes of hospitalised acute lower respiratory infections and meteorological factors in China: a retrospective study. The Lancet Planetary Health, 2021. 5(3): p. e154-e163.

16. $\mathrm{Li}, \mathrm{Y}$. , et al., Global patterns in monthly activity of influenza virus, respiratory syncytial virus, parainfluenza virus, and metapneumovirus: a systematic analysis. Lancet Glob Health, 2019. 7(8): p. e1031. 
17. Martin, E.T., et al., Multiple versus single virus respiratory infections: viral load and clinical disease severity in hospitalized children. Influenza \& Other Respiratory Viruses, 2015. 6(1): p. 71-77.

18. Price, O.H., et al., Using routine testing data to understand circulation patterns of influenza A, respiratory syncytial virus and other respiratory viruses in Victoria, Australia. Epidemiology and infection, 2019. 147: p. e221.

19. Haller, O., G. Kochs, and F. Weber, The interferon response circuit: induction and suppression by pathogenic viruses. Virology, 2006. 344(1): p. 119-130.

20. Aberle, J.H., et al., Single versus dual respiratory virus infections in hospitalized infants: impact on clinical course of disease and interferon-gamma response. Pediatric Infectious Disease Journal, 2005. 24(7): p. 605-10.

21. Legg, J.P., et al., Type 1 and type 2 cytokine imbalance in acute respiratory syncytial virus bronchiolitis. Am J Respir Crit Care Med, 2003. 168(6): p. 633-639.

22. Bendelja, K., et al., Predominant type-2 response in infants with respiratory syncytial virus (RSV) infection demonstrated by cytokine flow cytometry. Clinical \& Experimental Immunology, 2010. 121(2). 
Figures and Table

Fig.1 Total positive rate of 14 common respiratory pathogens in 470 Southern China

471

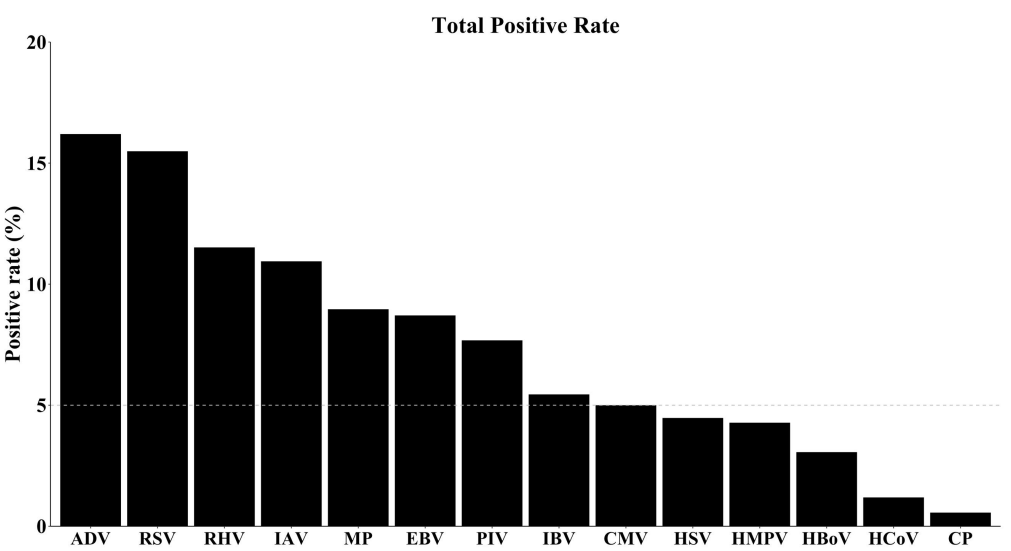

472

473

474

475

476

477

478

479

480

481

482

483

484

485

486

487

488

489 


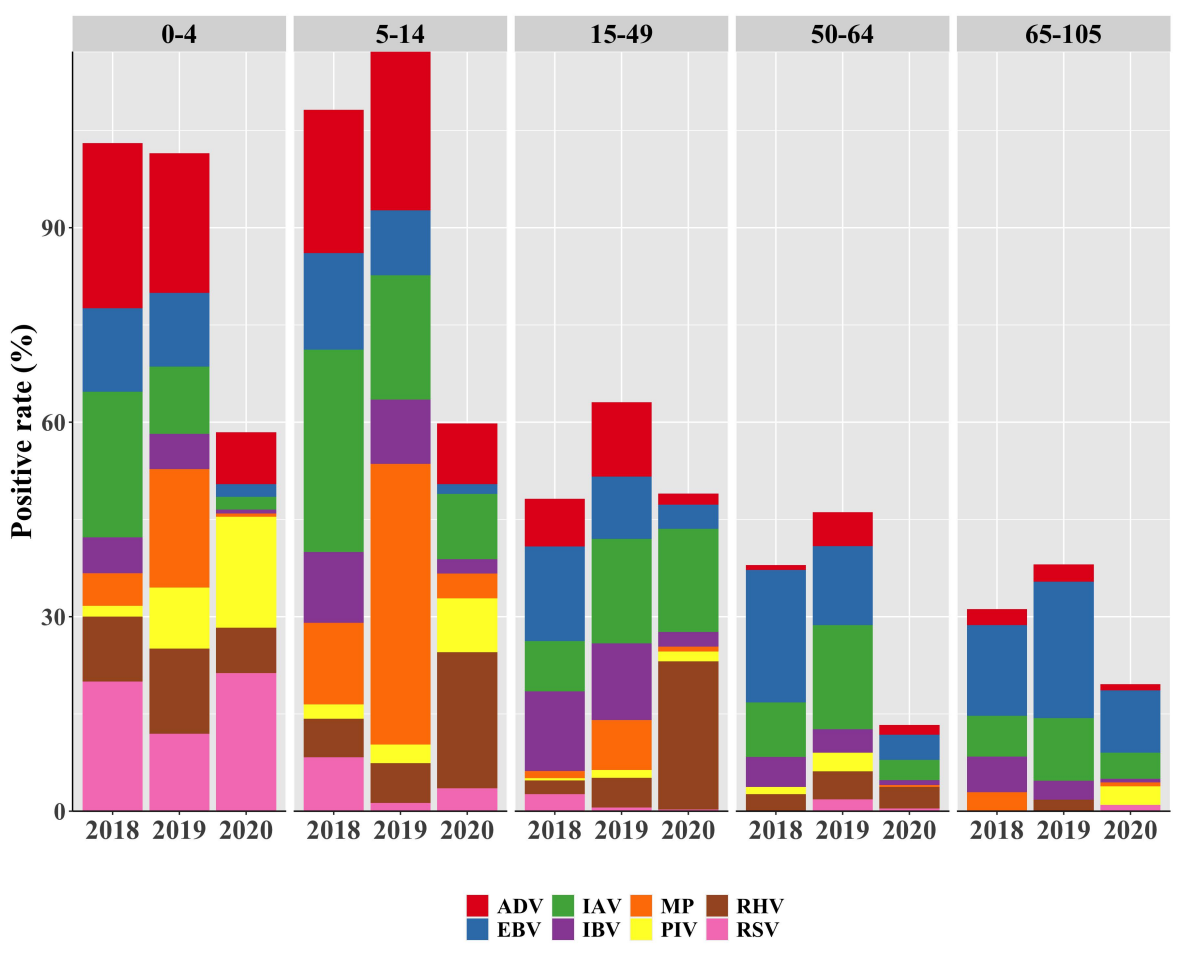

492

493

494

495

496

497

498

499

500

501

502

503

504

505

506 
Figure 3. The distribution of positive rate between inland and coastal cite in adult and children. *Chi square test, $\mathrm{P}<0.05$

A

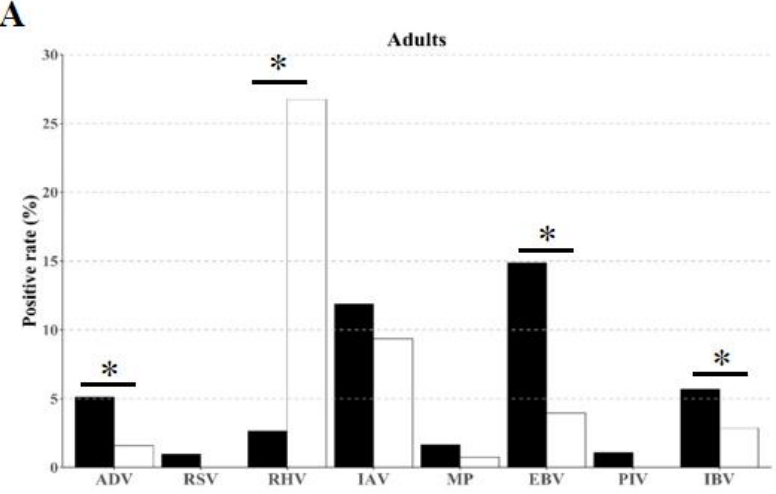

B

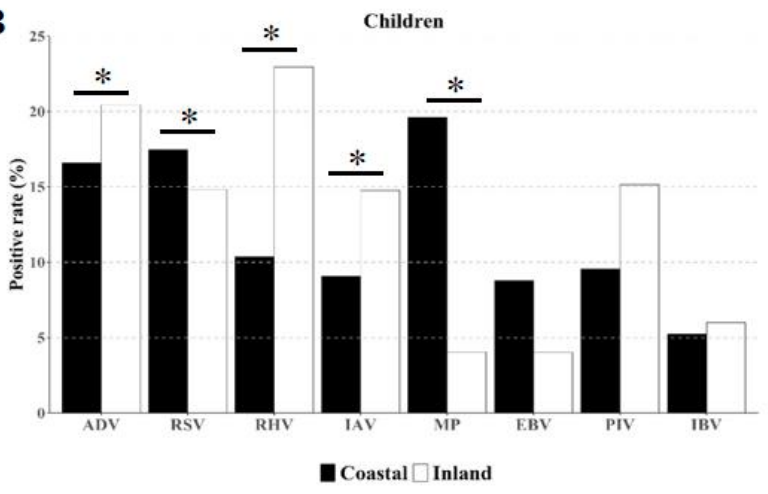

510

511

512

513

514

515

516

517

518

519

520

521

522 
Figure 4.Monthly distribution of pathogen infection in adults and children
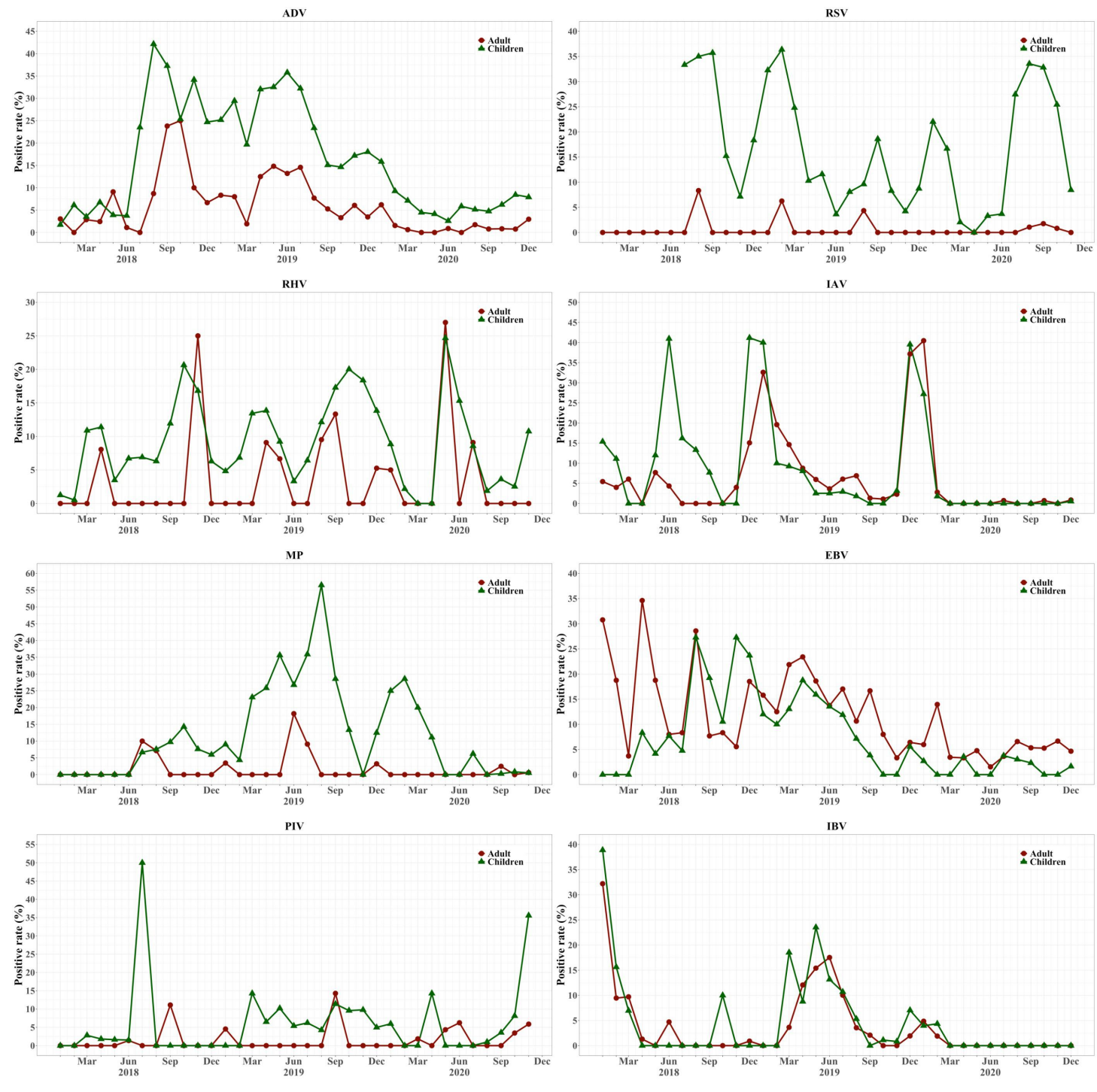


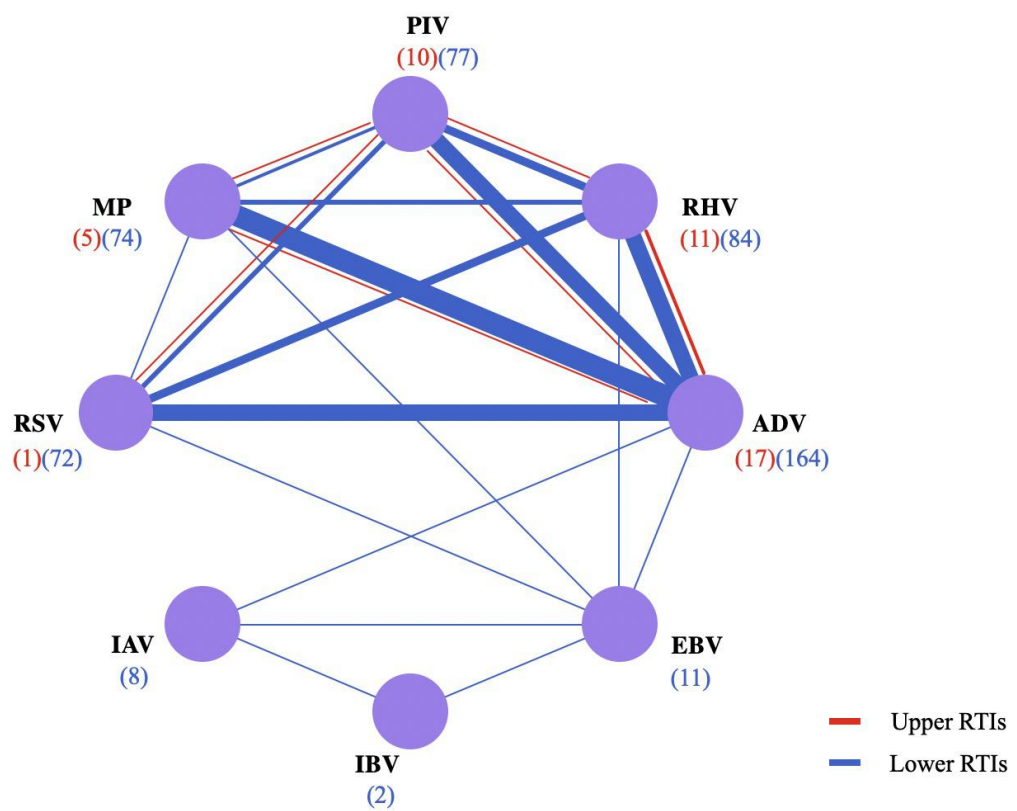


Table 1 Demographic characteristics of 134,552 RTIs patients from southern China

\begin{tabular}{|c|c|c|c|c|c|}
\hline Characteristic & $\begin{array}{l}\text { Total } \\
(\mathrm{n}= \\
134,552)\end{array}$ & $\begin{array}{l}\text { Adult } \\
(\mathrm{n}= \\
26,872)\end{array}$ & $\begin{array}{l}\text { Children } \\
(\mathrm{n}= \\
107,680)\end{array}$ & $\chi^{2}$ & $p$-value \\
\hline Sex & & & & 19.937 & $<0.05$ \\
\hline male & $\begin{array}{l}77710 \\
(57.75)\end{array}$ & $\begin{array}{l}14094 \\
(52.45)\end{array}$ & $\begin{array}{l}63616 \\
(59.08)\end{array}$ & & \\
\hline female & $\begin{array}{l}54230 \\
(40.30)\end{array}$ & $\begin{array}{l}10362 \\
(38.56)\end{array}$ & $\begin{array}{l}43868 \\
(40.74)\end{array}$ & & \\
\hline Age & & & & & $<0.05$ \\
\hline mean $(\mathrm{sd})$ & $\begin{array}{l}12.74 \\
(21.02)\end{array}$ & $\begin{array}{l}50.47 \\
(19.80)\end{array}$ & $3.32(3.18)$ & & \\
\hline Season & & & & 3970.534 & $<0.05$ \\
\hline spring (3-5) & $\begin{array}{l}23613 \\
(17.55)\end{array}$ & $\begin{array}{l}7434 \\
(27.66)\end{array}$ & $\begin{array}{l}16179 \\
(15.03)\end{array}$ & & \\
\hline summer $(6-8)$ & $\begin{array}{l}32245 \\
(23.96)\end{array}$ & $\begin{array}{l}5974 \\
(22.23)\end{array}$ & $\begin{array}{l}26271 \\
(24.40)\end{array}$ & & \\
\hline autumn(9-11) & $\begin{array}{l}44496 \\
(33.07)\end{array}$ & $\begin{array}{l}5412 \\
(20.14)\end{array}$ & $\begin{array}{l}39084 \\
(36.30)\end{array}$ & & \\
\hline winter (12-2) & $\begin{array}{l}34198 \\
(25.42)\end{array}$ & $\begin{array}{l}8052 \\
(29.96)\end{array}$ & $\begin{array}{l}26146 \\
(24.28)\end{array}$ & & \\
\hline Region & & & & 593.585 & $<0.05$ \\
\hline coastal areas & $\begin{array}{l}112771 \\
(83.81)\end{array}$ & $\begin{array}{l}21206 \\
(78.91)\end{array}$ & $\begin{array}{l}91565 \\
(85.03)\end{array}$ & & \\
\hline
\end{tabular}




\begin{tabular}{|c|c|c|c|c|c|}
\hline inland & $\begin{array}{l}21781 \\
(16.19)\end{array}$ & $\begin{array}{l}5666 \\
(21.09)\end{array}$ & $\begin{array}{l}16115 \\
(14.97)\end{array}$ & & \\
\hline \multicolumn{6}{|l|}{ Disease (N) } \\
\hline URI & $\begin{array}{l}10571 \\
(7.86)\end{array}$ & $\begin{array}{l}850 \\
(3.16)\end{array}$ & $9721(9.03)$ & 1036.486 & $<0.05$ \\
\hline bronchitis & $\begin{array}{l}11842 \\
(8.80)\end{array}$ & $\begin{array}{l}342 \\
(1.27)\end{array}$ & $\begin{array}{l}11500 \\
(10.68)\end{array}$ & 2377.349 & $<0.05$ \\
\hline pneumonia & $\begin{array}{l}34658 \\
(25.76)\end{array}$ & $\begin{array}{l}2675 \\
(9.95)\end{array}$ & $\begin{array}{l}31983 \\
(29.70)\end{array}$ & 4388.427 & $<0.05$ \\
\hline \multicolumn{6}{|c|}{$\begin{array}{l}\text { Positive for } \\
\text { pathogen } \\
\text { test(a/n,\%) }\end{array}$} \\
\hline ADV & $\begin{array}{l}7234 / 44680 \\
(16.19)\end{array}$ & $\begin{array}{l}129 / 3119 \\
(4.14)\end{array}$ & $\begin{array}{l}7105 / 41561 \\
(17.10)\end{array}$ & 359.088 & $<0.05$ \\
\hline RSV & $\begin{array}{l}2435 / 15730 \\
(15.48)\end{array}$ & $\begin{array}{l}8 / 1268 \\
(0.63)\end{array}$ & $\begin{array}{l}2427 / 14462 \\
(16.78)\end{array}$ & 232.428 & $<0.05$ \\
\hline RHV & $\begin{array}{l}2523 / 21924 \\
(11.51)\end{array}$ & $\begin{array}{l}44 / 884 \\
(4.98)\end{array}$ & $\begin{array}{l}2479 / 21040 \\
(11.78)\end{array}$ & 38.577 & $<0.05$ \\
\hline IAV & $\begin{array}{l}969 / 8863 \\
(10.93)\end{array}$ & $\begin{array}{l}657 / 5623 \\
(11.68)\end{array}$ & $\begin{array}{l}312 / 3240 \\
(9.63)\end{array}$ & 8.910 & $<0.05$ \\
\hline MP & $\begin{array}{l}471 / 5260 \\
(8.95)\end{array}$ & $\begin{array}{l}17 / 1456 \\
(1.17)\end{array}$ & $\begin{array}{l}454 / 3804 \\
(11.93)\end{array}$ & 149.737 & $<0.05$ \\
\hline EBV & $\begin{array}{l}242 / 2782 \\
(8.70)\end{array}$ & $\begin{array}{l}153 / 1605 \\
(9.53)\end{array}$ & $\begin{array}{l}89 / 1177 \\
(7.56)\end{array}$ & 3.322 & 0.08 \\
\hline PIV & $329 / 4290$ & $10 / 974$ & $319 / 3316$ & 78.515 & $<0.05$ \\
\hline
\end{tabular}




\begin{tabular}{|l|l|l|l|l|l|}
\hline & $(7.67)$ & $(1.03)$ & $(9.62)$ & & \\
\hline IBV & $442 / 8130$ & $285 / 5168$ & $157 / 2962$ & 0.168 & 0.72 \\
\hline & $(5.44)$ & $(5.51)$ & $(5.30)$ & & \\
\hline CMV & $140 / 2806$ & $93 / 1799$ & $47 / 1007$ & 0.344 & 0.62 \\
\hline HSV & $(4.99)$ & $(5.17)$ & $(4.67)$ & & \\
\hline HMPV & $115 / 2576$ & $79 / 1649$ & $36 / 927$ & 1.145 & 0.33 \\
\hline HBoV & $(4.46)$ & $(4.79)$ & $(3.88)$ & & \\
\hline HCoV & $348 / 8156$ & $1 / 276$ & $347 / 7880$ & 10.662 & $<0.05$ \\
\hline & $(4.27)$ & $(0.36)$ & $(4.40)$ & & \\
\hline CP & $69 / 2261$ & $1 / 586$ & $68 / 1675$ & 22.193 & $<0.05$ \\
\hline & $(3.05)$ & $(0.17)$ & $(4.06)$ & & \\
\hline & $22 / 1863$ & $16 / 1395$ & $6 / 468$ & 0.055 & 1.00 \\
\hline & $(1.18)$ & $(1.15)$ & $(1.28)$ & & \\
\hline & $29 / 5231$ & $6 / 1070$ & $23 / 4161$ & 0.001 & 1.00 \\
\hline & $(0.55)$ & $(0.56)$ & $(0.55)$ & & \\
\hline
\end{tabular}


565 Table 2 Top three pathogens detected in different age group

\begin{tabular}{llllll}
\hline & 0-4 & $5-14$ & $15-49$ & $50-64$ & $65-105$ \\
\hline 2018 & ADV, IAV, RSV & IAV, ADV, EBV & EBV, IBV, IAV & EBV, IAV, IBV & EBV, IAV, IBV \\
2019 & ADV, MP, RSV & MP, ADV, IAV & IAV, ADV, IBV & IAV, EBV, ADV & EBV, IAV, IBV \\
2020 & RSV, PIV, ADV & RHV, IAV, ADV & RHV, IAV, EBV & EBV, RHV, IAV & EBV, IAV, PIV \\
\hline
\end{tabular}


Table 3 Co-infection pattern in Upper RTIs and Lower RTIs

\begin{tabular}{|c|c|c|c|}
\hline Clinical diagnosis & \multicolumn{2}{|c|}{ Co-infection } & $\mathrm{N}$ (proportion) \\
\hline \multirow[t]{6}{*}{ Upper RTIs } & ADV & RHV & $8(36.36)$ \\
\hline & ADV & PIV & $5(22.73)$ \\
\hline & ADV & MP & $4(18.18)$ \\
\hline & RHV & PIV & $3(13.64)$ \\
\hline & RSV & PIV & $1(4.55)$ \\
\hline & PIV & MP & $1(4.55)$ \\
\hline \multirow[t]{16}{*}{ Lower RTIs } & ADV & MP & $48(19.51)$ \\
\hline & ADV & PIV & $38(15.45)$ \\
\hline & ADV & RHV & $36(14.63)$ \\
\hline & ADV & RSV & $36(14.63)$ \\
\hline & $\mathrm{RHV}$ & RSV & 18(7.32) \\
\hline & RHV & PIV & $18(7.32)$ \\
\hline & RSV & PIV & $12(4.88)$ \\
\hline & $\mathrm{RHV}$ & MP & $11(4.47)$ \\
\hline & PIV & MP & $9(3.66)$ \\
\hline & RSV & MP & $5(2.03)$ \\
\hline & IAV & EBV & $4(1.63)$ \\
\hline & ADV & IAV & $3(1.22)$ \\
\hline & ADV & EBV & $3(1.22)$ \\
\hline & RSV & EBV & $1(0.41)$ \\
\hline & $\mathrm{RHV}$ & EBV & $1(0.41)$ \\
\hline & MP & EBV & $1(0.41)$ \\
\hline
\end{tabular}




\begin{tabular}{|l|l|l|}
\hline IBV & EBV & $1(0.41)$ \\
\hline IAV & IBV & $1(0.41)$ \\
\hline
\end{tabular}


Figures

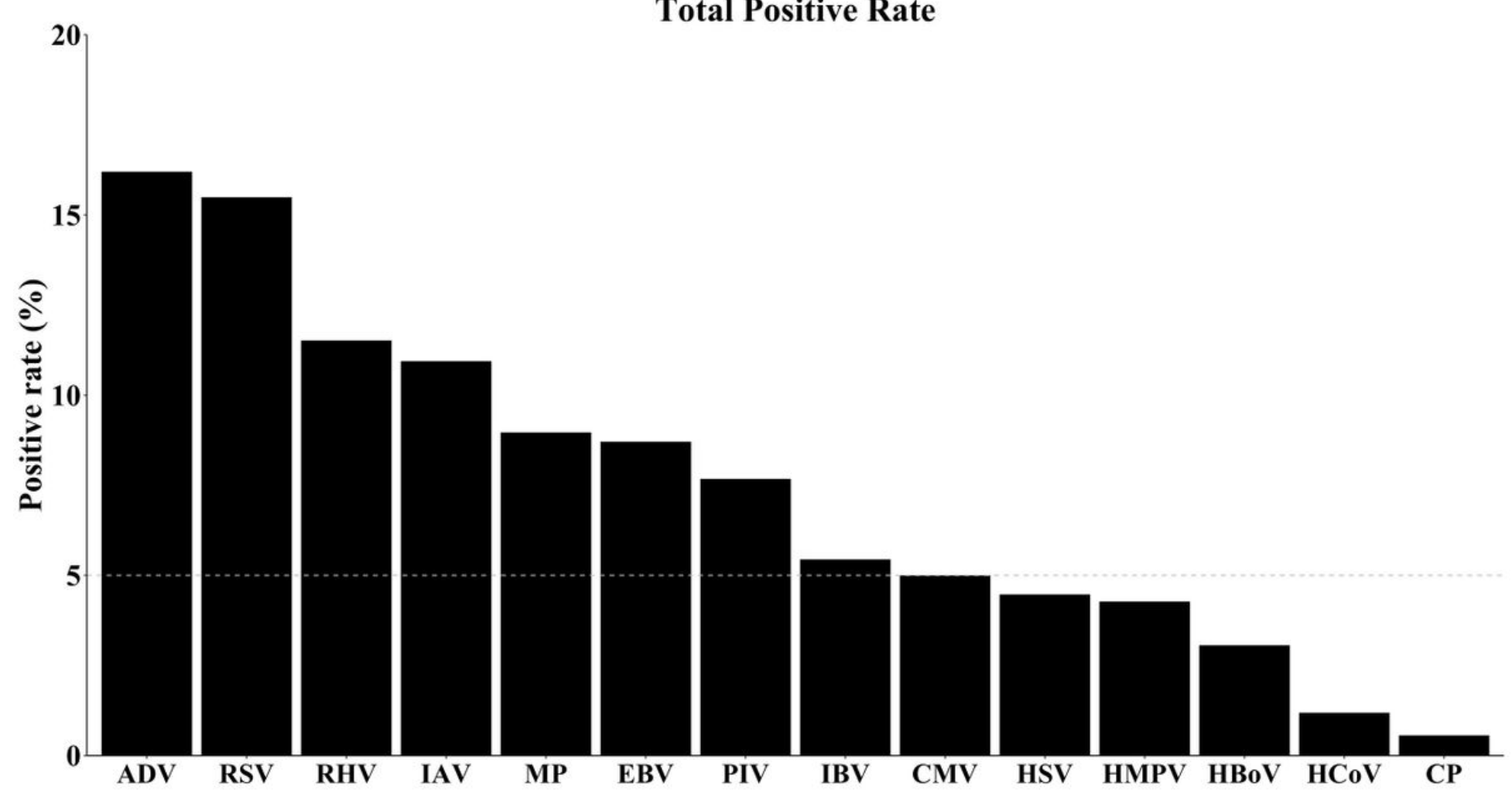

Figure 1

Total positive rate of 14 common respiratory pathogens in Southern China 


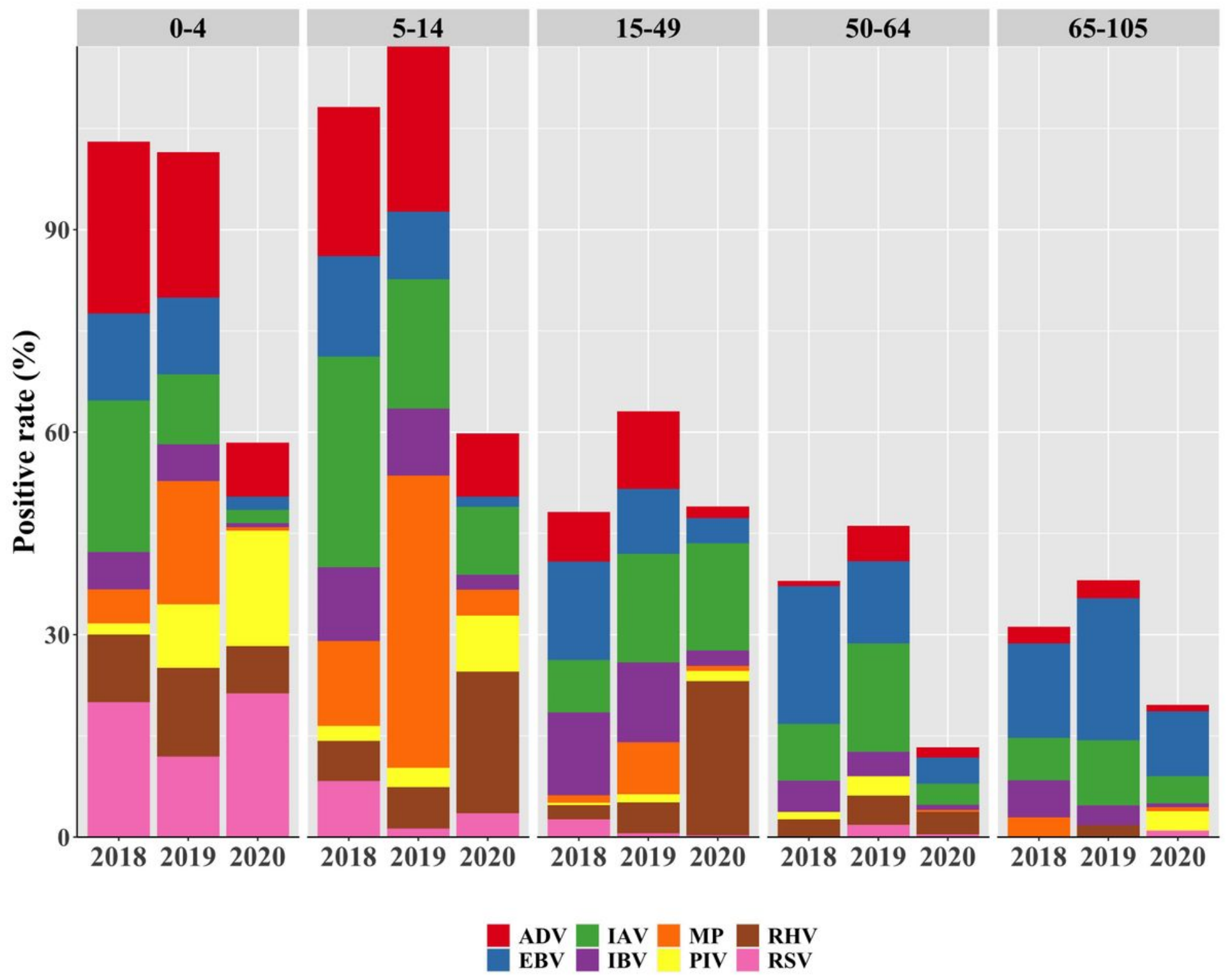

Figure 2

Age distribution of pathogen infection in 2018, 2019, 2020 
A

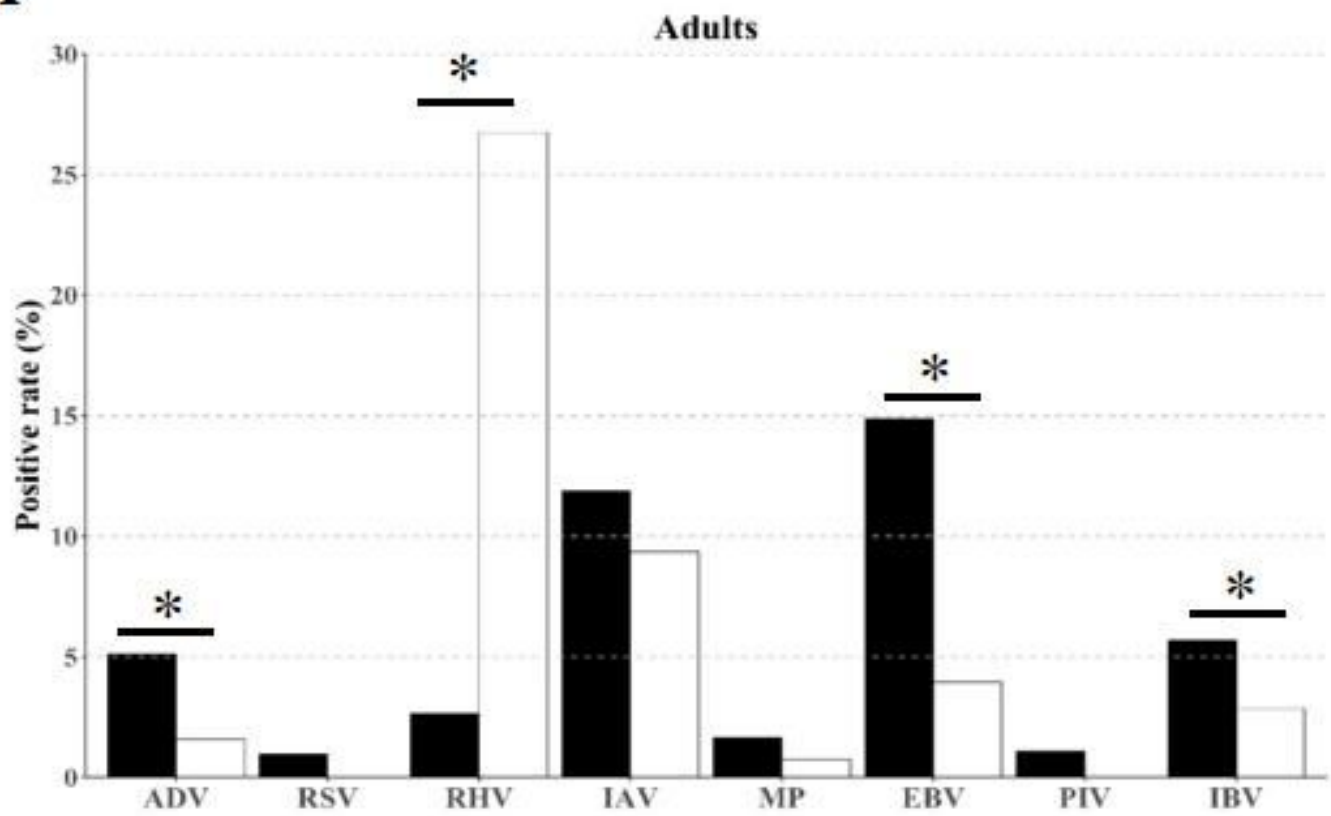

B

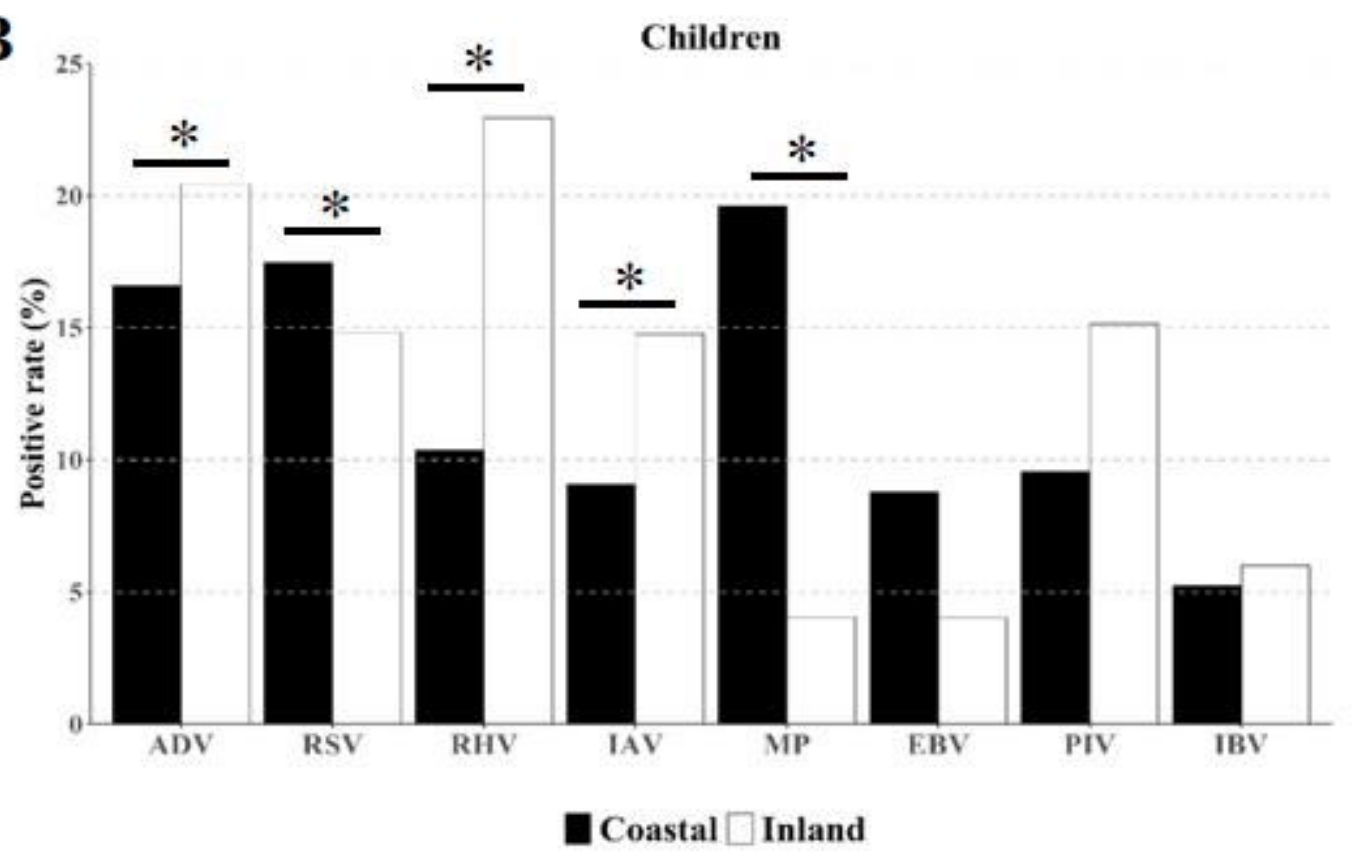

Figure 3

The distribution of positive rate between inland and coastal cite in adult and children. ${ }^{*}$ Chi square test, $\mathrm{P}<0.05$ 

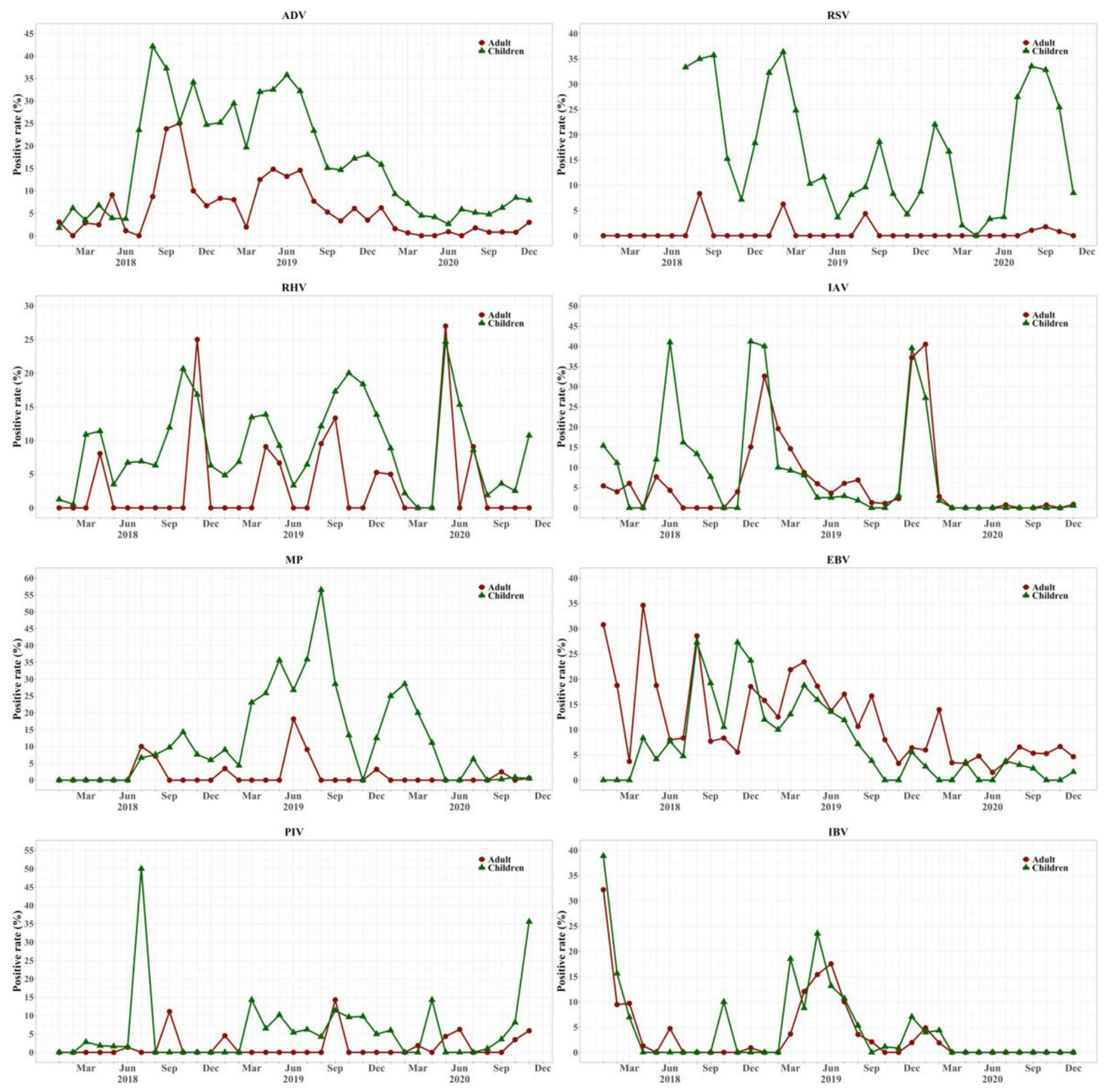

Figure 4

Monthly distribution of pathogen infection in adults and children 


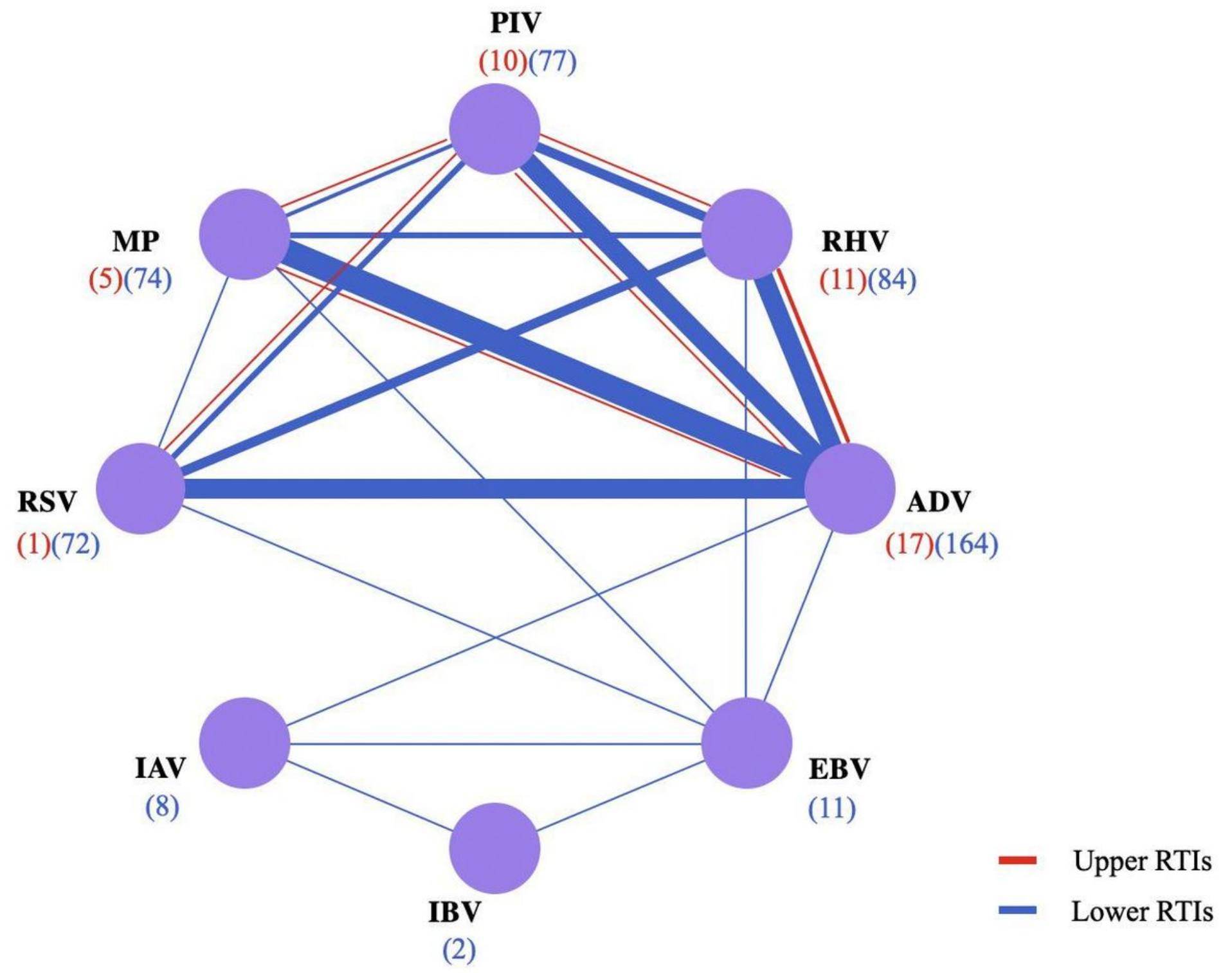

Figure 5

Poly-infection in patients with Upper RTIs and Lower RTIs 